BANCA D'ITALIA

E U R O S I S T E M A

Questioni di Economia e Finanza

(Occasional Papers)

Finance and creative destruction: evidence for Italy

by Francesca Lotti and Francesco Manaresi 

13 BANCA D'ITALIA

E U ROS I S T E M A

\section{Questioni di Economia e Finanza}

(Occasional papers)

Finance and creative destruction: evidence for Italy

by Francesca Lotti and Francesco Manaresi

Number 299 - December 2015 
The series Occasional Papers presents studies and documents on issues pertaining to the institutional tasks of the Bank of Italy and the Eurosystem. The Occasional Papers appear alongside the Working Papers series which are specifically aimed at providing original contributions to economic research.

The Occasional Papers include studies conducted within the Bank of Italy, sometimes in cooperation with the Eurosystem or other institutions. The views expressed in the studies are those of the authors and do not involve the responsibility of the institutions to which they belong.

The series is available online at www.bancaditalia.it .

ISSN $1972-6627$ (print)

ISSN 1972-6643 (online)

Printed by the Printing and Publishing Division of the Bank of Italy 


\title{
FINANCE AND CREATIVE DESTRUCTION: EVIDENCE FOR ITALY
}

\author{
by Francesca Lotti ${ }^{*}$ and Francesco Manaresi ${ }^{*}$
}

\begin{abstract}
In this paper we provide new evidence on the relationship between market concentration in the banking industry and firm dynamics. In Italy, in the case of a banking merger or acquisition, the antitrust authorities can require the sale of bank branches if the joint market share of the banks involved in the merger exceeds a specific threshold. We exploit this feature to carry out RDD estimates of (i) the effect of intervention by antitrust authorities on banking market concentration, and (ii) the effect of the level of bank concentration on various measures of firm dynamics. The results show that, in those areas where the authorities forced branch sales, firm's entry rates increase, reallocation of employees from incumbent to entrant firms is higher, and the survival rate of newly formed businesses increases. The overall allocative efficiency, as measured by an Olley-Pakes decomposition of labor productivity, is found to improve.
\end{abstract}

JEL Classification: G21, L11, M13.

Keywords: bank competition, firm dynamics, entry, exit, firm size, regression discontinuity.

\section{Contents}

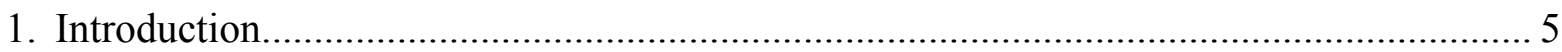

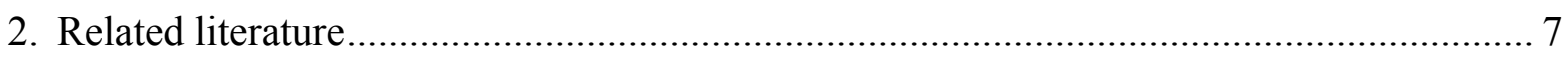

3. The institutional setting: Banks M\&A and Antitrust Interventions in Italy ..................... 10

4. The empirical strategy: identifying the effect of competition on firm dynamics .............. 12

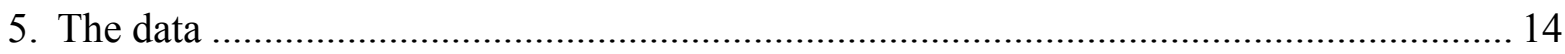

6. The effect of antitrust interventions on bank competition after an M\&A .......................... 16

7. The effect of bank competition on firm dynamics ....................................................... 19

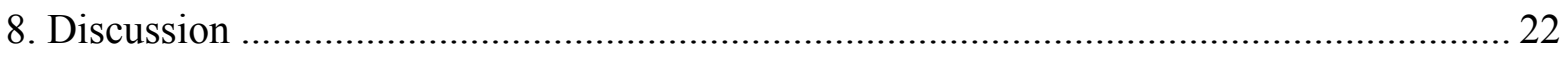

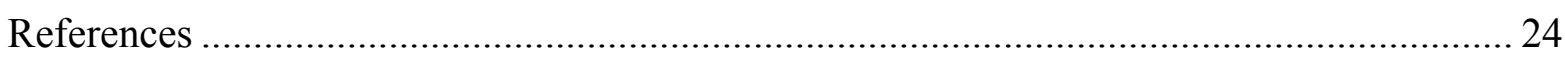

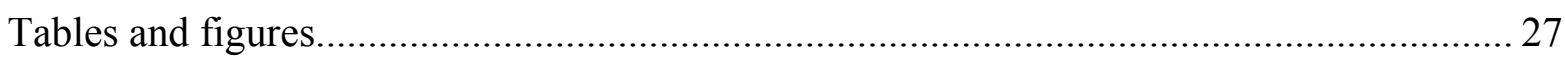

\footnotetext{
Bank of Italy, DG Economics, Statistics and Research, francesca.lotti@bancaditalia.it francesco.manaresi@bancaditalia.it
} 



\section{Introduction}

Firms' dynamics, i.e. the processes of firm entry, exit, survival and growth, has a notable role in determining growth and aggregate productivity, and understanding the frictions that hamper this process of reallocation, is central not only to policy makers. According to conventional wisdom, conditional on survival, new firms are typically more efficient and more productive than average incumbents, while exiting firms are less so. This phenomenon, known also as churning, is the main responsible for the process of job-creation and job-destruction within an economy (Haltiwanger, 2012). Even if, to a certain extent, some degree of churning is physiological, it is legitimate to ask whether the intensity of the entry/exit process and of market selection responds to other factors rather than to the perception of market opportunities or the business cycle only. A large literature has focused on the key role of financial frictions, providing robust evidence that broader and deeper financial markets foster the process of creative destruction 11 Several scholars have then tried to qualify this general finding, by looking at the role of specific microeconomic features of the credit market 2

In this paper, we focus on the role of bank market structure. In particular, we study how credit market concentration affects the process of firm entry/exit and improve the allocation of resources towards the most productive firms. To do this, we need an exogenous source of variation in market concentration. We find this source by exploiting a peculiar feature of the Italian regulatory framework for bank mergers-and-acquisition (M\&A) events. In each Italian province, whenever the joint share of deposits of the banks involved in the M\&A exceeds 15\%, the antitrust authority may impose the sale of some branches in order to reduce the anti-competitive impact of the

\footnotetext{
${ }^{1}$ See Matsuyama (2007) for a review of theoretical and empirical findings. Among the most recent contributions see Midrigan and Xu (2014) and Moll (2014).

${ }^{2}$ See Levine (1997) for a review.
} 
M\&A.

This institutional setting gives rise to a Regression Discontinuity (RD) framework: using detailed data on credit granted by each bank in each Italian province for the period 1996-2008, we show that the antitrust intervention results in a lower increase in market concentration after the M\&A in provinces immediately above the $15 \%$ threshold with respect to provinces below it.

We then look at how this intervention impacts on various measures of firm dynamics. For this purpose, we use yearly data on entry, exit, and employment of all Italian firms at the sector-province levels. We find that the yearly number of entrants increases discontinuously by around $4 \%$ at the threshold. This increase is accompanied by the shrinking of incumbent firms (notably those with less than 10 employees). While labor gains and losses balance-out, the allocative efficiency of employment, measured by an OlleyPakes decomposition of labor productivity, improves. New entrants are also more likely to survive at least five years.

According to our estimates, the intervention induces the sale of around 10 bank branches per province (as a reference, consider that, on average, there are 366 bank branches in each province and that, after an M\&A event, the newly formed banking group has 77 branches per province). Back-ofthe-envelope calculations suggest that the aggregate impact at the province level is in the order of 50 new firms per year in each province (the average yearly inflow of new firms is around 1,200 per province). The improvement in allocative efficiency at the sector-province level equals 1 percentage point of the covariance between firm size and its labor productivity, i.e. around $6 \%$ of a standard deviation.

The remainder of the paper is organized as follows. Section 2 fits our paper into the related literature, highlighting our contributions. In Section 3 , we provide a description of the institutional setting that we exploit for our 
identification strategy (outlined in Section 4). Data description is in Section 5 , and in Section 6 we present the effect of antitrust interventions on banking competition. Section 7 shows the causal effect of bank competition on firms' dynamics, while in Section 8 we draw some preliminary conclusions and we describe how do we intend to shape the paper in the near future.

\section{Related literature}

Finance can help shaping the Schumpeterian process of creative destruction (Aghion and Howitt, 2009), by allowing new, more efficient firms to enter the market, forcing less efficient ones to exit, or it can be an impediment to entrepreneurship and growth. In a frictionless capital market in the spirit of Modigliani and Miller (1958), funds flow in such a way that the marginal product of capital is equated across every project in the economy. Needless to say, in the everyday world, there are plenty of distortionary forces that prevent things from working this well. As Stein (2003) points out, taxes and transactions costs are examples of such frictions, but perhaps the most pervasive and important factors influencing the efficiency of financial markets are those that arise from informational asymmetries and agency problems. In other words, financial frictions are a wedge between the return received by providers of financial capital and the cost of capital paid by businesses and consumers who use that capital (Hall, 2011). In this paper, we focus on the shocks to credit supply as a key driver of financial frictions, as argued by Kashyap et al. (1993). Credit supply typically responds to monetary policy decisions and to the level of competition in the banking sector. In those countries where firms heavily rely on banks for their funding, credit availability is a precondition for firms to start their activity and eventually to grow. Conventional theories of industrial organization predict that a greater competition in the banking industry makes more credit available and at lower interest rates, with an impact on the terms of credit to startups as well as 
well as the degree to which capital is allocated to the highest-quality projects (Levine, 1997). However, as Bonaccorsi di Patti and Dell'Ariccia (2004) underline, these models are not able to capture the explicit role that information plays in credit markets: in fact, using data on Italian banks and firms, they find that an increase in bank competition may reduce the supply of credit to opaque borrowers by worsening the effects of adverse selection, moral hazard and hold-up problems. In particular, they find that bank competition results less favorable to the emergence of new firms in industrial sectors where informational asymmetries are more important. In a subsequent work, Cetorelli and Peretto (2012) explore further the informational contents of the bank-firm relationship. They find that more banks, i.e. higher levels of competition, lead to higher quantity of credit available, but less incentives for the banks to offer those relationship services that might improve the likelihood of success of investment projects.

However, bank deregulation, hence an increase in competition, is found to have first-order effects on the allocation of capital to large firms in France (Bertrand et al., 2007) and on the rate of birth of new firms in the US (Black and Strahan, 2002; Kerr and Nanda, 2009, 2010). In particular, Bertrand et al. (2007) find that banks were less willing to keep financing, or to bail out, poorly performing firms after the French banking reforms of 1985. As a result, French firms in sectors with a greater reliance on bank finance were more likely to go under restructuring.

Also, the US branch banking deregulations provide a particularly useful laboratory to study the effect of bank competition on firm dynamics, in particular on entry. Prior to liberalization, US banks faced multiple restrictions on geographic expansion both within and across states. As reported by Kerr and Nanda (2009), the most restrictive regulation, known as unit banking, limited each bank to a single branch. From the Seventies through the mid-Nineties, banks experienced significant liberalization in the possibility to open branches and to expand across state lines, either through new branches 
or through acquisitions. Greater bank competition and markets for corporate control due to US deregulations are thought to have improved allocative efficiency by allowing capital to flow more freely towards projects yielding the highest returns. Moreover, although the number of banks fell in absolute values during this period, the number of bank branches increased considerably, reflecting greater competition and increased consumer choice in local markets. From a theoretical perspective, these reforms would have had a strong positive effect on entrepreneurship if startups faced substantial credit constraints. Moreover, since entrepreneurs typically face fewer non-bank options for financing themselves, a more efficient allocation of capital within the banking industry should have led to larger increases in greenfield entry relative to facility expansions by existing firms if startups faced barriers in their ability to raise sufficient external capital to grow (the extensive margin). In this framework, Black and Strahan (2002), Cetorelli and Strahan (2006), and Kerr and Nanda (2009) find a significant increase in entrepreneurship subsequent to interstate branch banking deregulation. In addition to these changes at the extensive margin, Kerr and Nanda (2010) also find that startups were likely to be larger at entry relative to their maximum size in the first four years of operation, suggesting that the reforms have an effect on the intensive margin as well. With respect to the approach adopted by Kerr and Nanda (2009 and 2010), we take a step forward, in the sense that we use, as identification strategy, the pro-competitive effects of authorities' interventions after merger and acquisition operations in the banking industry that followed a period of intensive deregulation. In our view, such interventions represent an exogenous change in the market structure that leads to a decrease in concentration and to an increase in competition. The details of the institutional setting are explained in details in Section3. 


\section{The institutional setting: Banks M\&A and Antitrust Interventions in Italy}

The Italian banking system, originally composed mostly of public banks, undertook a massive reform in the early Nineties. In 1990, the Law 287 provided for the transformation of public banks into joint stock companies, This transformation eased the subsequent privatization, which started in 1992. The reforming process reached its culprit in 1993, with the approval of the Consolidated Law on Banking (legislative decree no. 385/1993). The newly privatized banks started a significant process of mergers and acquisitions (M\&A, henceforth) which reshaped credit market competition: from 1995 until the onset of the crisis in 2007, 742 M\&As took place among Italian banks. These events had to be preemptively authorized by the Bank of Italy (BoI). The BoI authorized the prospective M\&A on a case-by-case basis, after having received an evaluation of its potential impact on competition by the Antitrust Authority (AA).

The competitive impact of the M\&A's was, in fact, relevant. Figure 1 plots the average (log) Heirfindahl-Hirschmann index (HHI, henceforth) of the deposits market measured at the province level before and after an M\&A, for the period 1996-2008. The M\&A was associated with a significant increase in HHI (around 3\% in the first year, i.e. $30 \%$ of a within-province standard deviation). The HHI then decreased in the following years, yet after 4 years it was still $1.5 \%$ higher than before the M\&A.

On March 1996, the BoI and the AA signed an agreement that set the rules and procedures to be followed in the preemptive evaluation of an M\&A. The agreement defined the "relevant geographic markets" in which the competitive impact of the M\&A had to be evaluated: the impact on the deposit market had to be evaluated at the province level, while the one on the loans 
market had to be estimated at the broader regional level ${ }^{3}$ According to the agreement, in each of these two markets, the BoI has to measure the consolidated joint market share of the banks involved in the M\&A, and provide this data to the AA for evaluation. The agreement states that the impact of the M\&A shall be considered "important" for competition in deposit market if the joint market share of deposits at the province level exceeds $15 \%$, while it should be considered relevant in regions where the joint market share of loans exceeds 15\%.4 Since 1996, no M\&A exceeded the 15\% threshold in the regional loan market. Conversely, exceeding the $15 \%$ threshold in the provincial deposits market was more common. To appreciate it, we consider all the province-level events of M\&A: we restrict our observations to provinces where both banks involved in the M\&A were present in the year before the M\&A. Over the period 1996-2008 we are able to identify 3,763 of such province-level events. Figure 2 plots the distribution of the combined deposit share of the banks involved in the M\&A, as measured in the year before the event. Around $8 \%$ of our sample (311 observations) lie above the $15 \%$ threshold.

All provinces where the joint market share lied above the threshold were analyzed in detail by the AA. The AA may then impose the prospective merged banks to sell some branches in order to reduce the anti-competitive impact of the M\&A. We do not have (yet) the data on all the cases in which the AA forced the sale of some branches. Yet, preliminary inspection of the AA analyses shows that forced sales of branches were indeed imposed in

\footnotetext{
${ }^{3}$ An Italian province is a locality more or less equivalent to a non-sparsely-populated county in the United States. It corresponds to the NUTS 3 level of Eurostat classification. In the period under exam, there were 103 provinces in Italy with a minimum of 89 thousand and a maximum of 3.5 million inhabitants. A region corresponds to the NUTS 2 level.

${ }^{4}$ This agreement was in order until 2005, when the Law 262/2005 ended the period of shared competencies: all antitrust interventions were attributed to the AA. Yet, both the definition of the relevant markets and the use of the $15 \%$ threshold were preserved by the Authority in its subsequent interventions. For this reason, we consider the period 1996-2007 for our analysis, stopping just before the onset of the financial crisis.
} 
several cases.5 Yet, in the next Section, we discuss the relevant identifying assumptions needed to use the $15 \%$ threshold as an instrumental variable for a change in bank competition at the provincial level. We then present an empirical model to identify the intention-to-treat effect of bank competition on firm dynamics.

\section{The empirical strategy: identifying the ef- fect of competition on firm dynamics}

Estimating the causal effect of bank competition on firm dynamics is a daunting task. For instance, a simple correlation between firm entry/exit rates and the HHI is likely to yield biased results due to endogeneity issues. To cite a few, more banks are likely to accrue to higher-income provinces, and these province may also have a more dynamic entrepreneurial environment. Higher firm dynamics may also attract new competitors in the banking industry, thus raising problems of simultaneity. Ultimately, the sole reliable strategy to identify this causal effect using observational data is by exploiting an instrumental variable approach.

We consider an M\&A event that combines the share of deposits of two previously separated banks, thus increasing the HHI in the local (provincial) market. The 1996 agreement between the BoI and the AA, regulates how these institutions may intervene in such an event: if the joint market share of the two banks before the M\&A exceeds the $15 \%$ threshold, the institutions may force the sale of branches to decrease the post-M\&A share of the merged banks below $15 \%$.

To simply formalize the setting. Let $\tilde{s}_{0}=$ be the the joint share of the two

\footnotetext{
${ }^{5}$ All documents are available (in Italian) from the website of the AA: http://www.agcm.it/. In the year 2000, for instance, out of the 12 cases in which the M\&A involved joint market shares above the threshold, forced sales were imposed $30 \%$ of the times.
} 
banks before the M\&A, and $s_{1}$ the share after it. The tilde superscript signals that the variable is computed by summing the shares of two autonomous banks. Let us assume that forced sale of branches always takes place above the $15 \%$ threshold, and never below it. Then the function $s_{1}=f\left(s_{0}\right)$ is simply $s_{1}=s_{0}$ if $s_{0}<=0.15$, and $s_{1}=0.15$ otherwise. Thus, the function should have a kink at $s_{0}=0.15$. Now, consider the HHI computed at time $t=\{0,1\}$ among banks $i$ : $H H I_{t}=\sum_{i} s_{t}$. Then, the kink should have a significant effect in the $(\log )$ change in HHI that is due to the M\&A. Although the actual impact of the antitrust intervention above the threshold on the change in HHI depends on how the share $\tilde{s}_{0}-0.15$ is reallocated to the market, we can expect $\Delta \log H H I$ to change discontinuously at the threshold.

We bring these conjectures to the data by using a simple regression discontinuity framework. Let $m$ be a specific M\&A event (for instance the merge between Banca Intesa and San Paolo-IMI bank), $t$ the year in which the M\&A takes place, and $p$ an Italian province. Define $K_{p m t}=1\left(\tilde{s}_{t-1}>0.15\right)$ a dummy taking value 1 for provinces where the joint market share of banks involved in the M\&A measured before the event is higher than 0.15. We then consider the following model for a dependent variable $D V_{p m t}$ as:

$$
D V_{p m t}=\alpha+\delta K_{p m t}+g\left(\left|\tilde{s}_{t-1}-0.15\right|\right)+\varepsilon_{p m t}
$$

where $g($.$) is a smoothed polynomial function in the (absolute) distance be-$ tween the joint market share and the threshold, and it is allowed to differ among the two sides of the threshold.

We exploit this model for two related exercises. First, we choose $D V_{p m t}=$ $\Delta \log H H I_{p m t}$ : in this case, the parameter $\delta$ measures the discontinuity in the change in competition observed at the threshold. For $\delta$ to be the causal effect of the (potential) antitrust interventions on bank competition, we need to assume that (i) there are no other confounding factors affecting bank 
competition that change discontinuously at the threshold (unconfoundedness), and (ii) banks do not position there market share strategically above or below the threshold (no strategic manipulation) 6 We present the results of this exercise in Section 6, where we also provide evidence in favor of the two assumptions.

Second, we consider a set of indicators of firm dynamics at the provincesector level as our dependent variables, such as entry/exit rates, size at entry, size of incumbents, survival rates of firms. In this case, the parameter $\delta$ would measure the intention-to-treat effect of a change in bank competition if the following additional assumption hold: (iii) antitrust interventions only affect firm dynamics through the change in competition (exclusion restriction). Results of this exercise are provided in Section 7 .

\section{The data}

For our analysis, we combine two sources of data. From the Supervisory Reports submitted by banks to the Bank of Italy, we collect yearly information on the total amount on deposit at each bank in each Italian province since 1992. From this source, we also obtain information on the number of branches each bank has in each province. Submitting this data is compulsory under the Italian law, and its quality is directly monitored by the Supervisory Division of the BoI. We match this information with the composition of each banking group in Italy at the end of each calendar year. For simplicity, we consider each autonomous bank to be a singular banking group. Thus, we measure the consolidated share of deposits and the consolidated number of branches in each province for each banking group.

\footnotetext{
${ }^{6}$ The distinction between (i) and (ii) is only for expositional purpose. Indeed, one may think about strategic positioning as inducing correlation between the threshold dummy and the error term in (1).
} 
We define an M\&A event as a movement of one bank from one group to another.For each acquisition event, we are able to identify the buyer and the acquired banks; in case of a merge event, to ease the exposition, we consider the buyer to be the biggest counterpart in terms of deposit market share. We then consider the two years before the M\&A event, and compute the average joint market share of banks involved in the M\&A. To clarify this point, let us assume that bank $A$ is an autonomous bank at $t-2$ and $t-1$. In year $t$, bank $\mathrm{A}$ is acquired by group $X$. We then compute the share of $X+A$ in the previous two years: this represent our running variable for the regression discontinuity design.

Other measures of bank competition, such as the HHI, are measured on the basis of the actual market shares of banking groups active in the market.

The second source of data is represented by the Italian National Social Insurance Agency (INPS), from which we obtain yearly data on all firms with at least one employee, active in manufacturing, construction or market services, as well as their employment level. For all incorporated firms (i.e., around one-third of the universe of firms), we also obtain value added from balance-sheet data. Our final dataset focuses on all M\&A events over the period 1996 (when the agreement was signed) to 2007 (i.e., before the financial crisis). For each event in each Italian provinces, both bank competition and firm dynamics variables are computed before (averaged over $t-1$ and $t-2$ ) and after (averaged over $t+1$ and $t+2$ ) the event. Table 1 shows the descriptive statistics of our dataset. There are in total 3,763 M\&A events at the province level over the period of observation. Firm dynamics, instead is measured at the province-sector-event level: thus the actual number of observations increases to slightly less than 80,000 . 


\section{The effect of antitrust interventions on bank competition after an M\&A}

We now provide evidence that bank competition changes discontinuously at the threshold set by the 1996 agreement, and provide evidence in favor of interpreting this discontinuity as the causal effect of the antitrust interventions.

According to our conjecture, the rules set in the 1996 agreement may affect the relationship between the pre-M\&A and the post-M\&A joint deposit market share of the banks involved in the event. In particular, the agreement allows banks to freely combine there shares below the $15 \%$ threshold, while the BoI intervention may force them to sell branches above it, in order to reduce their market share. To test this supposition, the left panel of Figure 3 plots the average joint deposit market share measured in the two years before the M\&A (horizontal axis), against the average market share of the newly merged banks in the two years after the M\&A (vertical axis). The graph depicts also kernel-weighted local second-order polynomial smoothed regression results (computed using a triangular kernel, with bandwidth chosen optimally according to the Imbens and Kalyanaraman (2012) criterion). The graph provides several intriguing results. First, below the threshold, the relationship is (as expected) linear and positive. Yet, the ex-post share is slightly higher than the ex-ante one. This may signal that in the two years after the M\&A, the group is able to increase slightly its market share. Most importantly for our analysis, right above the $15 \%$ threshold, the relationship becomes markedly flatter, as we conjectured in Section 3. In this preliminary graphical analysis, we do not infer the statistical significance of the kink. This will be tested explicitly in the regression analysis below. The right panel of Figure 3 provides evidence that the kink in ex-post market share is induced by the sale of branches. It plots our running variable against the difference 
between the post-M\&A number of branches of the new merged bank and the ex-ante number of branches of the acquired bank only. This difference declines markedly at the threshold.

Ultimately, the goal of the antitrust intervention is to limit the impact of the M\&A on the deposit market concentration. We test this by comparing the (log) increase in the HHI of the deposits market induced by the M\&A on the two sides of the threshold. The left panel of Figure 4 shows that this change is increasing in pre-M\&A joint deposit market share: this is a trivial result, as merging together two bigger shares will induce a larger increase in the HHI. More importantly, we observe a decrease at the threshold, which corresponds to the kink observed in the left panel of Figure 3. Thus, the antitrust intervention seems to be somehow effective in limiting deposit market concentration.

Nevertheless, the effect goes beyond the deposits market: focusing on total outstanding credit granted to firms by each bank, we compute the HHI at the province level. The results depicted in the right panel of Figure 4 shows that also credit market concentration is affected by the intervention on the deposit market. Additional results, not reported here for brevity, show that this effect is driven by credit lines and (partly) by loans backed by receivables. As pointed out by Alesina et al. (2013), these are the main tool for credit and liquidity management used by small firms, which is a relevant category when looking at firms' dynamics (in fact, the one for which we estimate a significant effect, see Section 7). Conversely, the HHI of total loans, that includes both new and outstanding loans, does not change discontinuously at the threshold.

Table 2 provides local-linear regression results to test the statistical significance of these discontinuities. Notice that there are several potential problems with inference in the sample: several observations may belong to the same province, and several M\&A events may involve the same banking 
group. For this reason, we provide standard errors that are robust to serial correlation at the province and banking group levels. We test for the robustness of our findings using four different bandwidths chosen according to four different criteria: the afore-mentioned IK one (our preferred choice), the criterion proposed by Calonico et al. (2014), the one used by DesJardins and McCall (2014), and the cross-validation method of Ludwig and Miller (2007). The first panel of the Table shows that the change in the slope at the threshold is always significant and negative. The second panel shows that also the negative discontinuity in the change in number of branches is significant. Finally, the last two panels show that the effect on the change in HHI is negative and significant. The point estimates of the impact on the HHI of the deposits and credit markets are not directly comparable, as the average market concentration changes markedly between the two. Once standardized, the impact on the deposits market seems stronger than the one in the credit market (around 50\% and 30\% of a standard deviation, respectively).

As discussed in Section 4 , for the change in HHI to be attributed solely to the antitrust interventions two assumptions must hold: unconfoundedness at the threshold, and lack of strategic manipulation of the running variable by banks involved in the M\&A. To provide evidence in favor of the unconfoundedness hypothesis, Table 3 reports the local-linear regression estimate of the discontinuity at the threshold for various potential confounding factors, encompassing HHI in the deposit and loan markets, per-capita value added, and population density, all measured in the two years before the M\&A. The threshold dummy does not affect significantly any of these variables.

The possibility of strategic manipulation of the running variable may seem, prima facie, very likely in our setting. Banks know about the presence of the 15\% threshold, and in principle they can preemptively sell bank branches in order to ease the approval of an M\&A. Yet, notice that no M\&A has ever been rejected on the basis of the presence of market shares above the 
threshold: the AA and the BoI have, at best, condition the approval of the M\&A to the sale of bank branches. Now, if banks know that the authorities will (at worst) provide for such a conditional approval, then it would not be optimal to sell branches preemptively.

Moving from theoretical speculations to empirical analysis, we provide evidence against strategic manipulation of the running variable by using the McCrary (2008) test of sample density around the threshold. Figure 5 shows the graphical result: if anything there is a larger density above the threshold. Yet, the difference is not statistically significant at any conventional level $(p<0.33)$. In the next future, we plan to fully exploit the available information to test more robustly for the presence of strategic manipulation. Indeed, the Supervisory Report data contains the actual owner of each Italian branch in each year. Preemptive selling (or purchasing) of branches by banks involved in an M\&A may, thus, be directly testable.

\section{The effect of bank competition on firm dy- namics}

In this Section, we exploit the RDD to provide evidence of the intentionto-treat effect of bank competition on firm dynamics.

The first panel of Table 4 identifies the effect of the threshold on the $(\log )$ change in entrants using a local-linear regression (with optimal bandwidth according to the IK method). The first column reports pooled RDD results, while from the second to the fourth we include fixed-effects at the year, sector, and province levels. Both the point-estimate and significance of the coefficient of threshold dummy remain remarkably stable, thus providing indirect evidence in favor of the hypothesis that (around the threshold) the running variable is not correlated with observable and unobservable characteristics. The second panel of the Table shows evidence of the estimated effect on firm exit. The point-estimate is significantly smaller than the one on entry, and it 
is never statistically different from zero. Thus, contrary to the US evidence by Kerr and Nanda (2009), we found that an increase in bank competition raises the net entry of firms.7

Having identified an increase in entry of new firms, we start looking for evidence of changes in their average productivity. The first indicator that we explore is the change in average size at entry: which may be considered a proxy for this purpose inasmuch size and productivity are positively correlated. Yet, initial size may not differ much between firms, as their potential success in the market may be uncertain also to entrepreneurs. As the third panel of the Table shows, the estimated effect is never statistically different from zero: the increase in bank competition induces a higher number of firms to enter the market, yet the size of them is (on average) the same.

An alternative way of measuring the quality of the new entrants is by testing whether they are able to substitute, at least partially, the older ones. This is what we do in the fourth panel of Table 4 , where the dependent variable is now the $(\log )$ change in the average size of incumbent firms. In this case, we find a negative and significant effect of bank competition providing evidence that the increase in employment among new firms (mostly through the extensive margin) is compensated by a fall in employment among incumbent ones.

Tab yetle 5 look at the heterogeneity of this estimated effect by incumbent size: the negative effect seems to be driven by micro-firms (1-9 employees, first panel of the Table), while the effect among small, medium, and large firms (reported in the second and third panels of the Table) seem to be null.

The displacement of older firms by new entrants may not, per se, signal a process of "creative destruction". To test whether the higher turnover implies

\footnotetext{
${ }^{7}$ The estimated effect on net entry (delta-log Entry - delta-log Exit) is not reported here for the sake of brevity, but it is perfectly in line with the results obtained in the first two panels of Table 4 .
} 
a stronger allocative efficiency, we focus on the subsample of incorporated firms, for which we observe value added from balance-sheets. We decompose the growth rate of average labor productivity (value added per-worker) at the province-sector level using the standard methodology of Olley and Pakes (1996). Let $\phi_{w}$ be the average (log) labor productivity in each province-sector cell, then its change after the M\&A can be decomposed into:

$$
\Delta \phi_{w}=\Delta \phi_{u w}+\Delta A E
$$

where $\phi_{u w}$ is the unweighted mean of firm-level productivity, and $A E=$ $\operatorname{Cov}\left(\phi_{i}-\phi_{u w}, S_{i}-S_{u w}\right)$ is what is usually defined as "allocative efficiency": the covariance between firm productivity $\phi_{i}$ and its labor share $S_{i}$.

We test for the impact of the antitrust intervention on each element of the Olley-Pakes decomposition. Table 6 shows the estimates obtained from a model with sector, year, and province fixed-effects (results are robust to the omission of any of these controls). We fail to identify an effect on average productivity growth, yet we do find a significant increase in allocative efficiency: the covariance between size and productivity is found to increase by 1 percentage point (5.8\% of a standard deviation) above the threshold.

Finally, we consider the effects of the increase in bank competition over a longer time span. First, we focus on the cohort of firms that entering in the two years after the M\&A (those for which for which the threshold has a positive effect, according to Table 4). We then ask whether these firms have a larger survival rate at five years old. The result, provided in the first panel of Table 7, is an economically and statistically significant "yes!" : right after the threshold, the survival rate increases by around $4 \%$, i.e. around $17 \%$ of a standard deviation.

Second, we test whether there is a positive effect on exit over a longer time horizon: we look at the average number of exitors three and four years after the M\&A. The results reported in the second panel of Table 7 show some evidence (not very precisely estimated) of such an increase. This may be 
induced by previous incumbents now exiting the market after the initial downsizing. Yet, the evidence collected so far do not allow us to clearly provide evidence in favor or in contrast to this last conjecture.

\section{Discussion}

In this paper, we provide a novel identification strategy to gauge the causal effect of a change in banking market structure (as measured by the HHI) on firm dynamics. A 1996 agreement between the BoI and the AA set a peculiar rule for antitrust authority interventions in case of an M\&A between banks: the authorities may impose the sale of bank branches if the joint market share of the banks involved in the M\&A exceeds $15 \%$. We exploit this rule for a regression discontinuity design. We provide evidence that the rule determines a kink discontinuity in the relationship between the ex-ante and the ex-post joint market share, and that the kink translates into a discontinuity in the change in HHI induced by the M\&A.

Intention-to-treat estimates show that the antitrust-induced improvement in bank concentration positively affects firm dynamics, with a large number of entrant firms that induce a shrinking in the size of incumbent firms, and which are more likely to survive five or more years.

Having settled these preliminary findings, our research is going to proceed in several complementary directions. At one side, we shall strengthen the evidence in favor of our identification hypotheses by exploiting the detailed information on each bank branch to test for pre-M\&A strategic manipulation of the running variable. On another side, we will use information on price and quantity of credit drawn the Credit Register database at the BoI to identify the channels through which the estimated effects take place. Ideally, we would like to answer the following questions: i) does an increase in competition raises the quantity and/or lowers the price of credit? ii) how 
does credit allocation respond to an increase in bank competition? Is credit more likely to be reallocated among entrants or to incumbent firms? Finally, by combining firm demographics information with balance-sheet data, we can directly test whether the estimated effects on firm dynamics reflect changes in firm-level productivity. 


\section{References}

Aghion, P. and Howitt, P. (2009). The Economics of Growth. MIT Press.

Alesina, A. F., Lotti, F., and Mistrulli, P. E. (2013). Do women pay more for credit? evidence from italy. Journal of the European Economic Association, 11:45-66.

Bertrand, M., Schoar, A., and Thesmar, D. (2007). Banking Deregulation and Industry Structure: Evidence from the French Banking Reforms of 1985. Journal of Finance, 62(2):597-628.

Black, S. E. and Strahan, P. E. (2002). Entrepreneurship and Bank Credit Availability. Journal of Finance, 57(6):2807-2833.

Bonaccorsi di Patti, E. and Dell'Ariccia, G. (2004). Bank Competition and Firm Creation. Journal of Money, Credit and Banking, 36(2):225-51.

Calonico, S., Cattaneo, M. D., and Titiunik, R. (2014). Robust nonparametric confidence intervals for regression-discontinuity designs. Econometrica, 82(6):2295-2326.

Cetorelli, N. and Peretto, P. F. (2012). Credit quantity and credit quality: Bank competition and capital accumulation. Journal of Economic Theory, 147(3):967-998.

DesJardins, S. and McCall, B. (2014). The impact of the gates millennium scholars program on college and post-college related choices of high ability, low-income minority students. Economics of Education Review, 38:124138.

Hall, R. E. (2011). The High Sensitivity of Economic Activity to Financial Frictions. Economic Journal, 121(552):351-378. 
Haltiwanger, J. (2012). Job Creation and Firm Dynamics in the United States. In Innovation Policy and the Economy, Volume 12, NBER Chapters, pages 17-38. National Bureau of Economic Research, Inc.

Imbens, G. and Kalyanaraman, K. (2012). Optimal bandwidth choice for the regression discontinuity estimator. The Review of Economic Studies, $79(3): 933-959$.

Kashyap, A. K., Stein, J. C., and Wilcox, D. W. (1993). Monetary Policy and Credit Conditions: Evidence from the Composition of External Finance. American Economic Review, 83(1):78-98.

Kerr, W. R. and Nanda, R. (2009). Democratizing entry: Banking deregulations, financing constraints, and entrepreneurship. Journal of Financial Economics, 94(1):124-149.

Kerr, W. R. and Nanda, R. (2010). Banking Deregulations, Financing Constraints, and Firm Entry Size. Journal of the European Economic Association, 8(2-3):582-593.

Levine, R. (1997). Financial Development and Economic Growth: Views and Agenda. Journal of Economic Literature, 35(2):688-726.

Ludwig, J. and Miller, D. L. (2007). Does head start improve children's life chances? evidence from a regression discontinuity design. The Quarterly Journal of Economics, 122(1):159-208.

Matsuyama, K. (2007). Aggregate implications of credit market imperfections. NBER Working Papes, (13209).

Midrigan, V. and Xu, D. Y. (2014). Finance and Misallocation: Evidence from Plant-Level Data. The American Economic Review, 104(2):422-458. 
Moll, B. (2014). Productivity losses from financial frictions: Can selffinancing undo capital misallocation? The American Economic Review, 104(10):3186-3221.

Stein, J. C. (2003). Agency, information and corporate investment. In Constantinides, G., Harris, M., and Stulz, R. M., editors, Handbook of the Economics of Finance, volume 1 of Handbook of the Economics of Finance, chapter 2, pages 111-165. Elsevier. 
Tables and Figures 


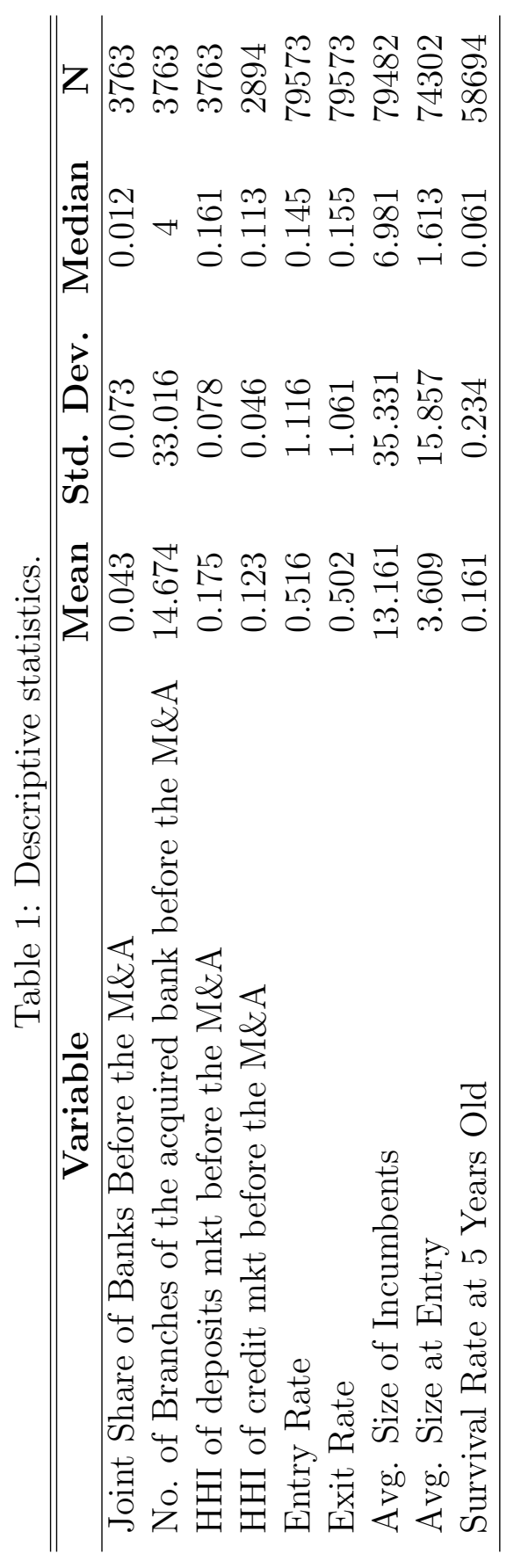




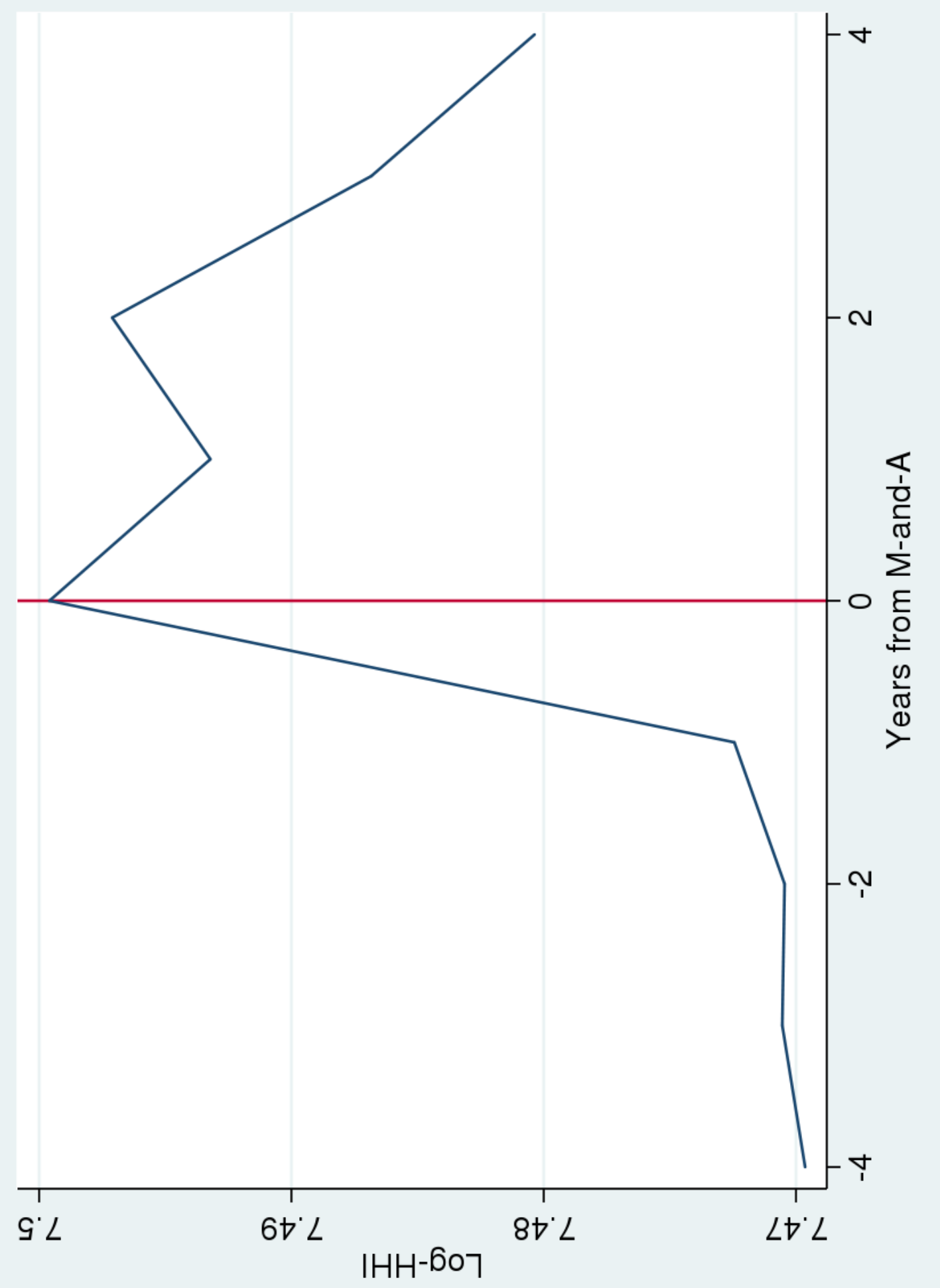

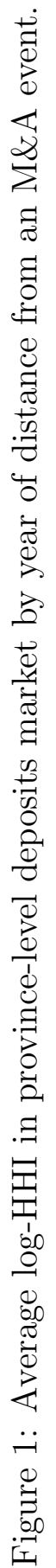




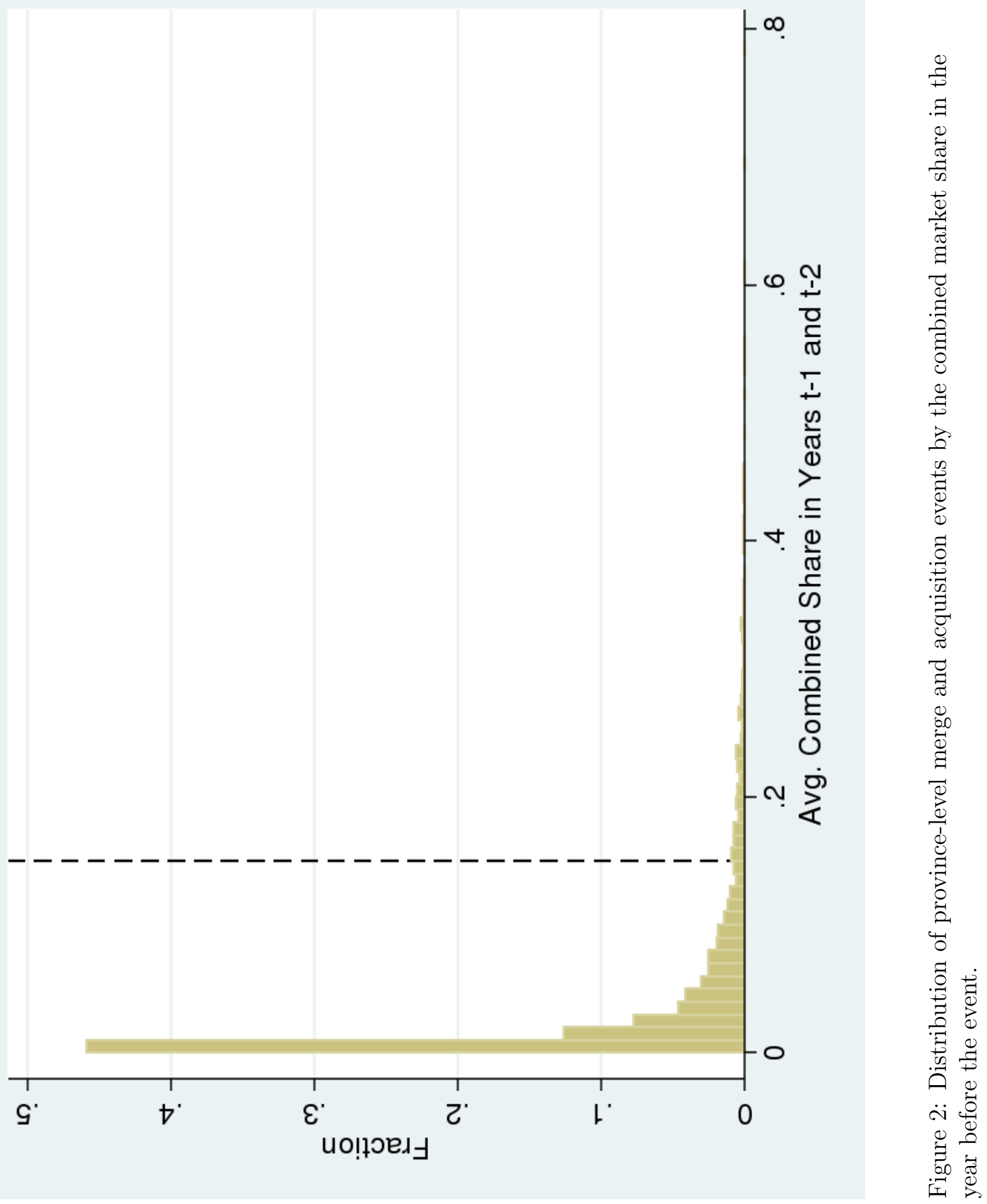




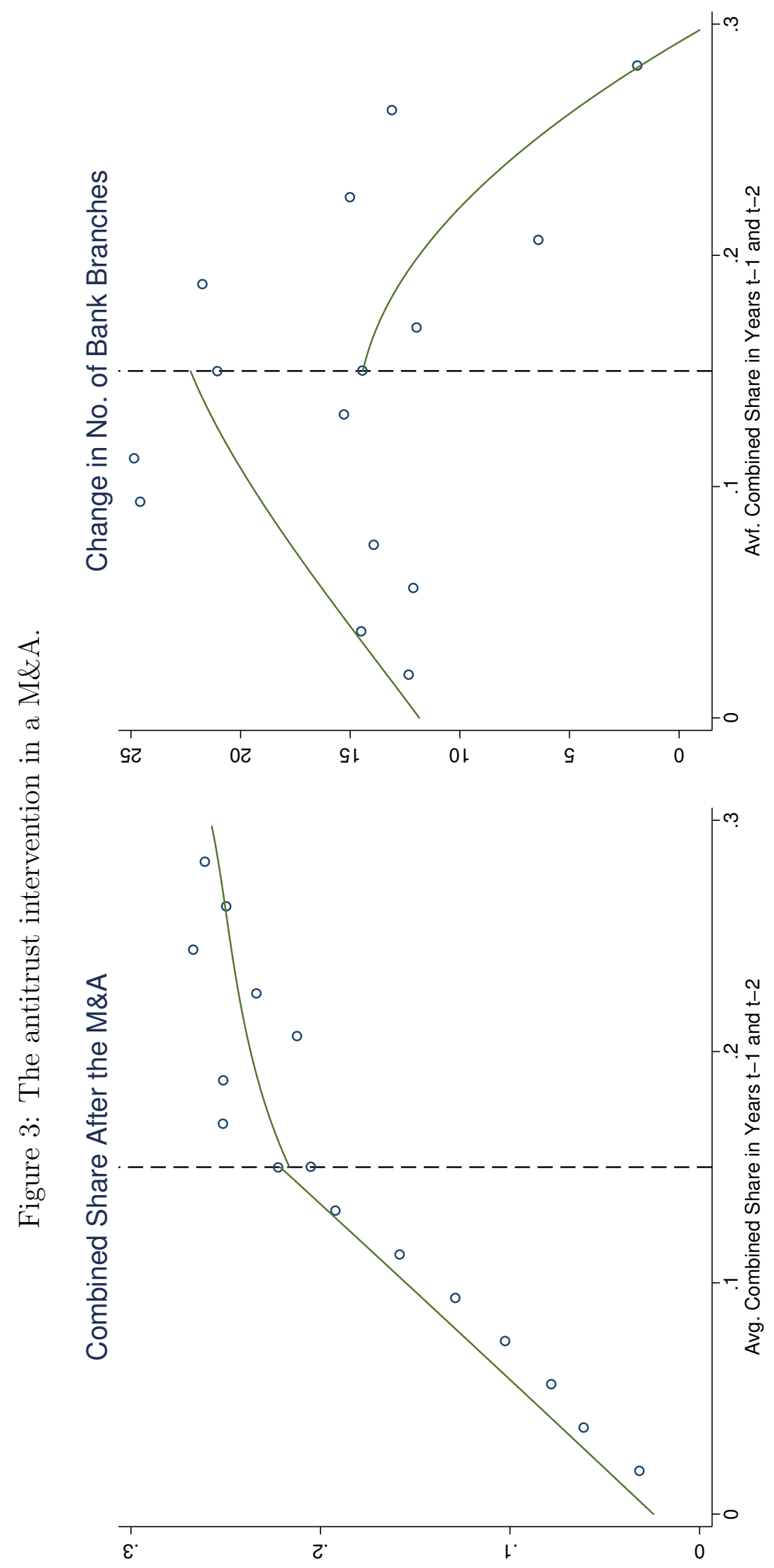




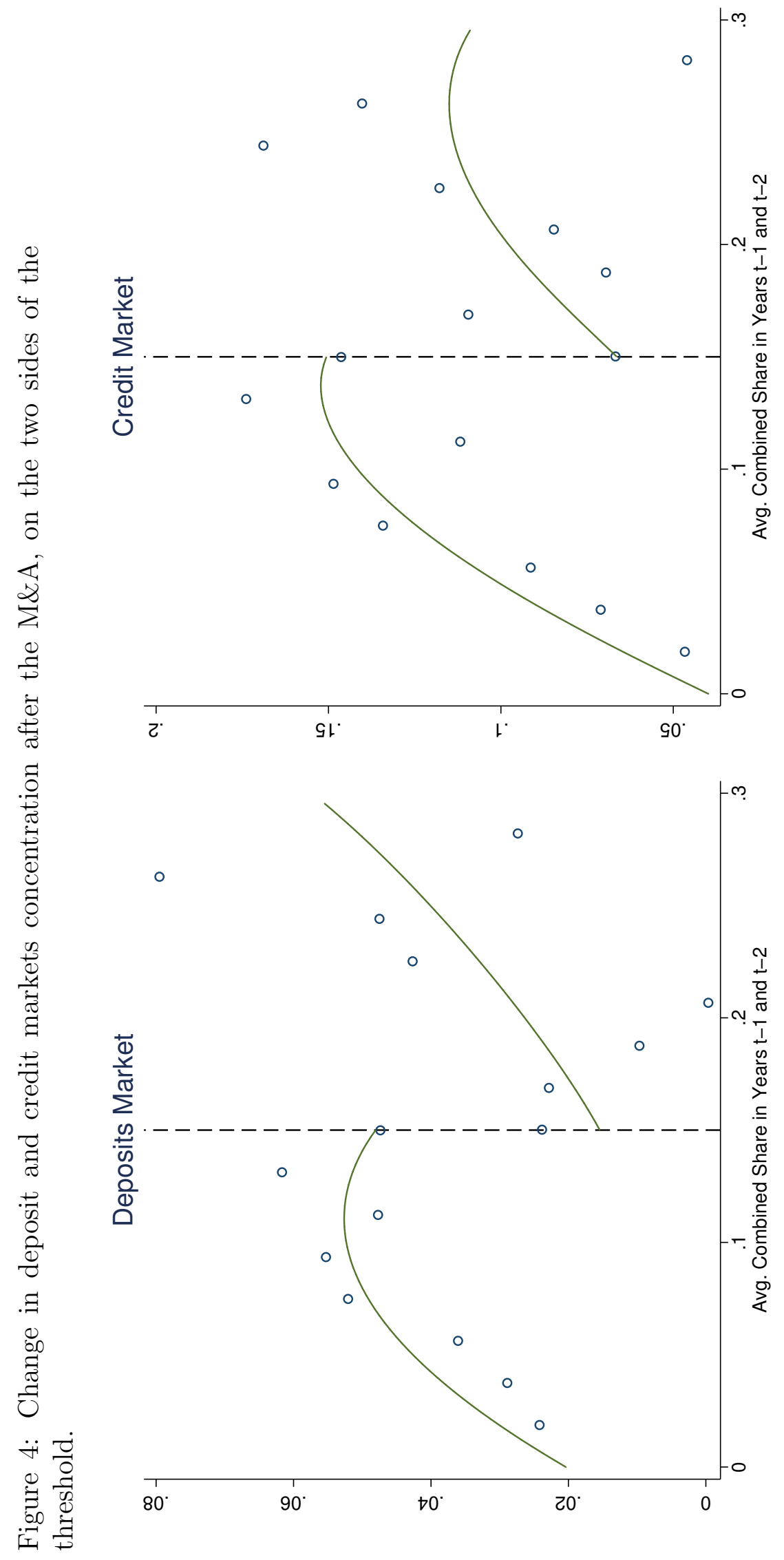




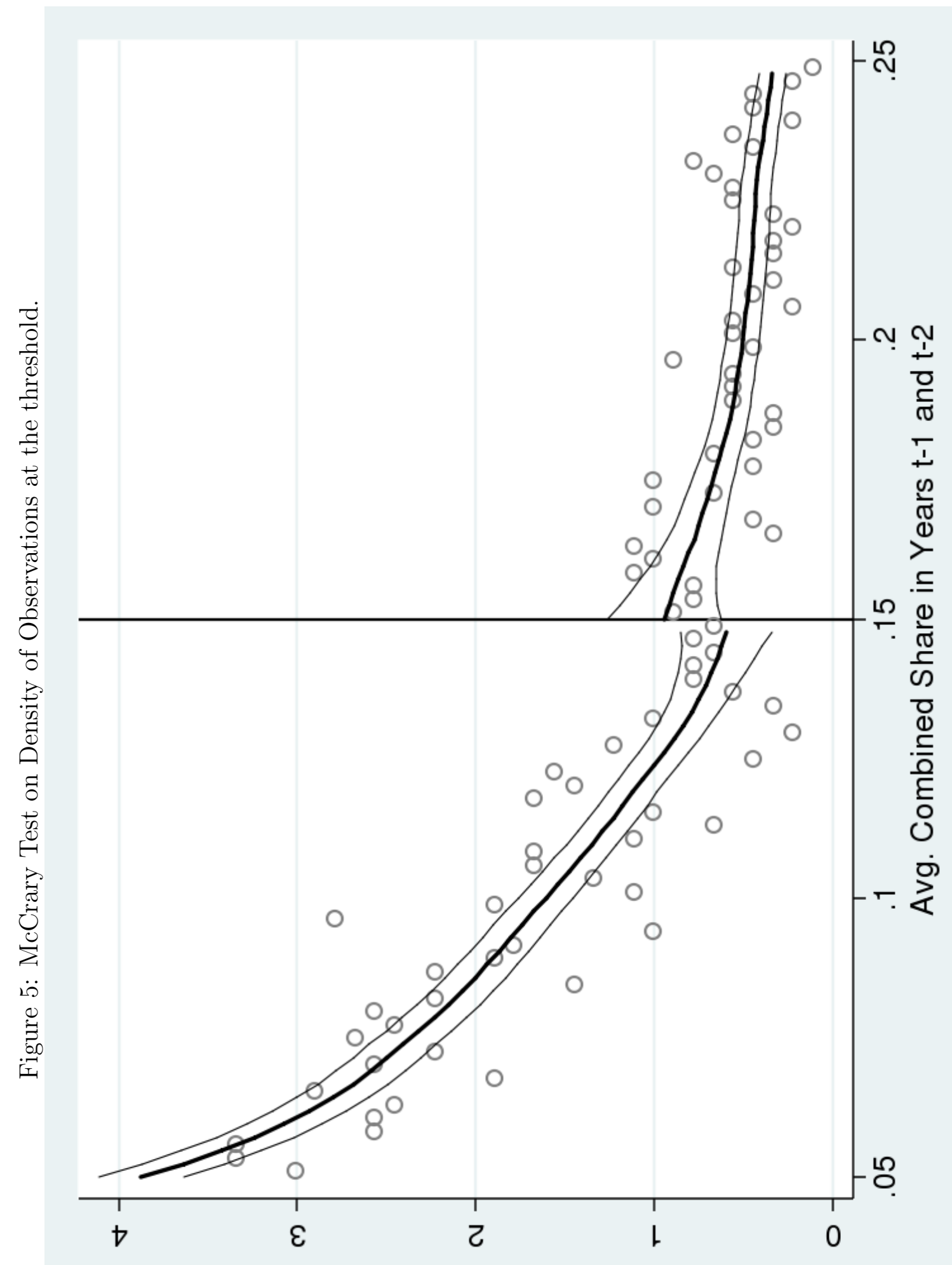


Table 2: Regression discontinuity evidence on the antitrust intervention.

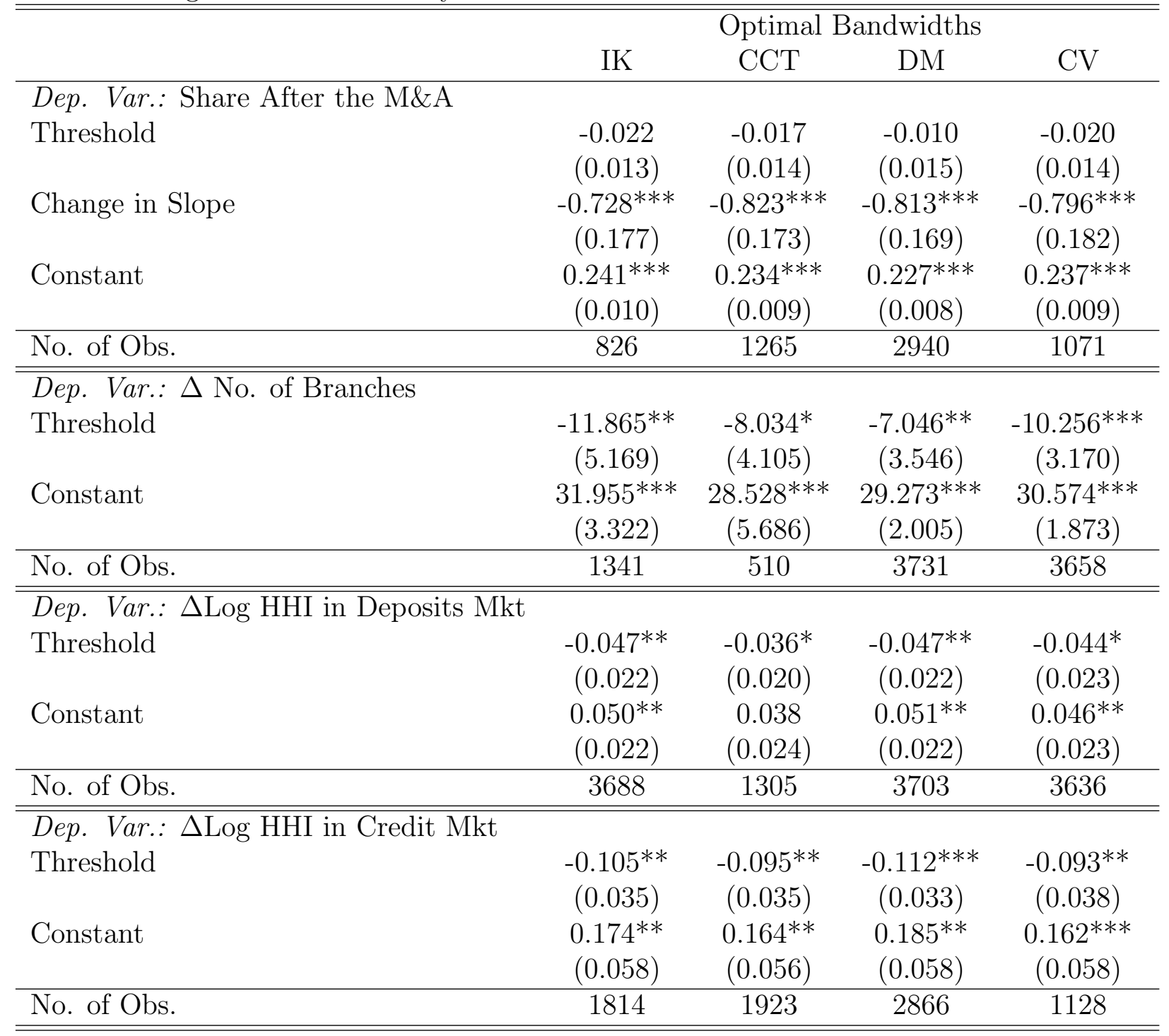




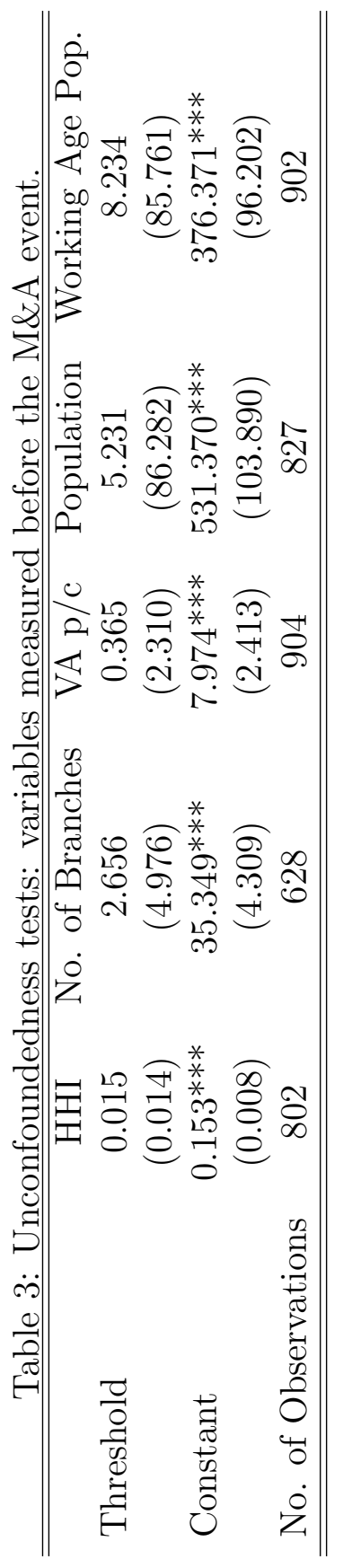


Table 4: Regression discontinuity results of the effect of bank competition on firm dynamics.

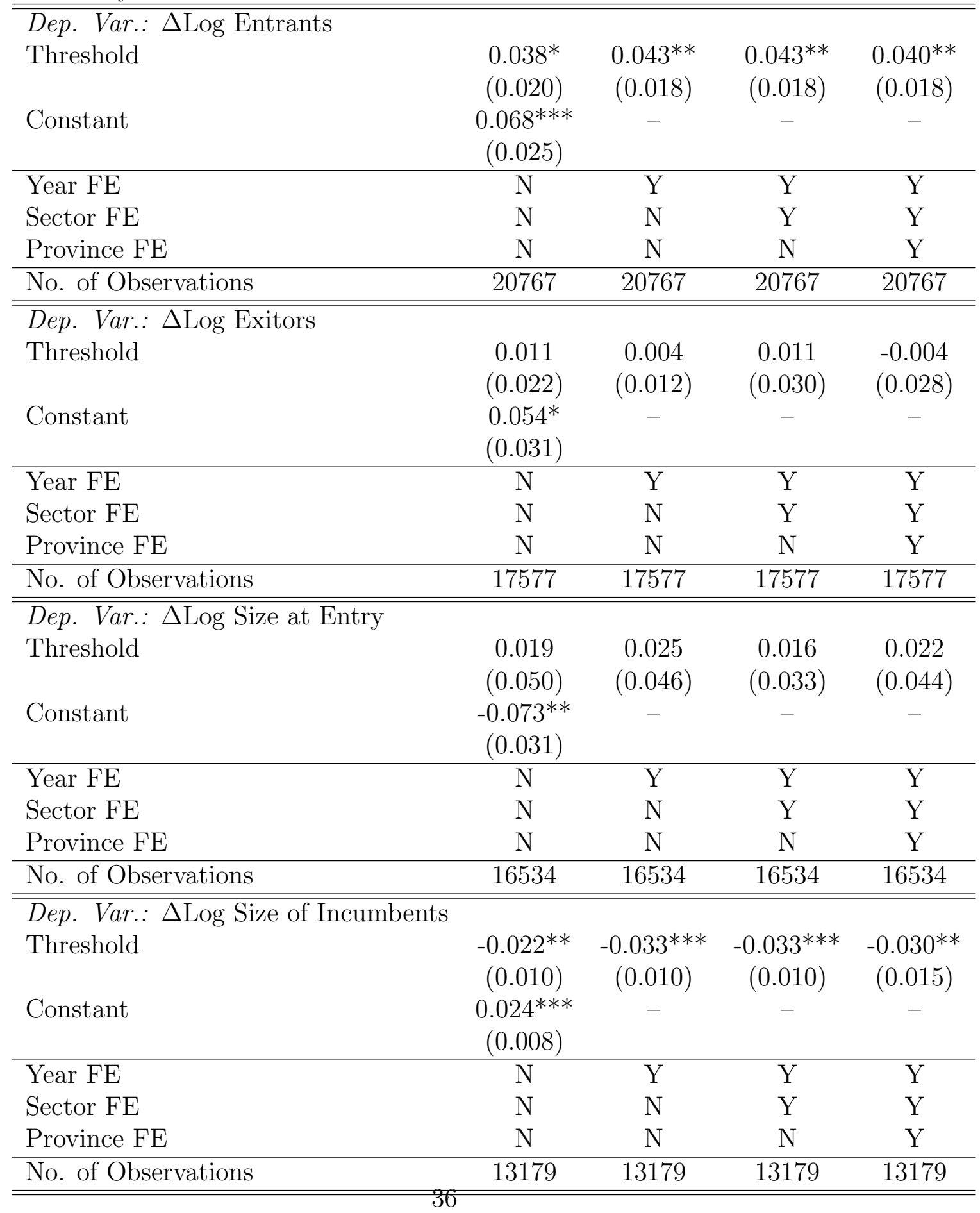


Table 5: Regression discontinuity results of the effect of bank competition on firm dynamics.

\begin{tabular}{lcccc}
\hline \hline Dep. Var.: $\Delta$ Log Size of Micro Firms & & & & \\
Threshold & $-0.024^{* *}$ & $-0.035^{* * *}$ & $-0.034^{* * *}$ & $-0.032^{* *}$ \\
& $(0.011)$ & $(0.008)$ & $(0.011)$ & $(0.014)$ \\
Constant & $0.026^{* * *}$ & - & - & - \\
& $(0.010)$ & & & \\
\hline Year FE & $\mathrm{N}$ & $\mathrm{Y}$ & $\mathrm{Y}$ & $\mathrm{Y}$ \\
Sector FE & $\mathrm{N}$ & $\mathrm{N}$ & $\mathrm{Y}$ & $\mathrm{Y}$ \\
Province FE & $\mathrm{N}$ & $\mathrm{N}$ & $\mathrm{N}$ & $\mathrm{Y}$ \\
\hline No. of Observations & 76236 & 76236 & 76236 & 76236 \\
\hline \hline Dep. Var.: $\Delta$ Log Size of Small-Medium Firms & & & & \\
Threshold & 0.001 & 0.000 & 0.002 & -0.001 \\
& $(0.006)$ & $(0.005)$ & $(0.004)$ & $(0.005)$ \\
Constant & 0.001 & - & - & - \\
& $(0.004)$ & & & \\
\hline Year FE & $\mathrm{N}$ & $\mathrm{Y}$ & $\mathrm{Y}$ & $\mathrm{Y}$ \\
Sector FE & $\mathrm{N}$ & $\mathrm{N}$ & $\mathrm{Y}$ & $\mathrm{Y}$ \\
Province FE & $\mathrm{N}$ & $\mathrm{N}$ & $\mathrm{N}$ & $\mathrm{Y}$ \\
\hline No. of Observations & 28700 & 28700 & 28700 & 28700 \\
\hline \hline Dep. Var.: $\Delta$ Log Size of Large Firms & \multicolumn{3}{|}{} & \\
Threshold & -0.000 & -0.001 & 0.001 & 0.007 \\
& $(0.007)$ & $(0.007)$ & $(0.012)$ & $(0.006)$ \\
Constant & $0.008^{* *}$ & - & - & - \\
& $(0.004)$ & & & \\
\hline Year FE & $\mathrm{N}$ & $\mathrm{Y}$ & $\mathrm{Y}$ & $\mathrm{Y}$ \\
Sector FE & $\mathrm{N}$ & $\mathrm{N}$ & $\mathrm{Y}$ & $\mathrm{Y}$ \\
Province FE & $\mathrm{N}$ & $\mathrm{N}$ & $\mathrm{N}$ & $\mathrm{Y}$ \\
\hline No. of Observations & 59581 & 59581 & 59581 & 59581 \\
\hline \hline
\end{tabular}


Table 6: Regression discontinuity results of the effect of bank competition on labor productivity decomposition.

\begin{tabular}{lccc}
\hline \hline Dep. Var.: & $\Delta \phi_{w}$ & $\Delta \phi_{u w}$ & $\Delta \mathrm{AE}$ \\
Threshold & 0.004 & -0.003 & $0.010^{* *}$ \\
& $(0.005)$ & $(0.004)$ & $(0.004)$ \\
\hline Year FE & $\mathrm{Y}$ & $\mathrm{Y}$ & $\mathrm{Y}$ \\
Sector FE & $\mathrm{Y}$ & $\mathrm{Y}$ & $\mathrm{Y}$ \\
Province FE & $\mathrm{Y}$ & $\mathrm{Y}$ & $\mathrm{Y}$ \\
\hline No. of Observations & 15190 & 15190 & 15190 \\
\hline \hline
\end{tabular}

Table 7: Regression discontinuity results of the effect of bank competition on firm dynamics.

\begin{tabular}{|c|c|c|c|c|}
\hline \multicolumn{5}{|l|}{ Dep. Var.: $\Delta$ Survival at 5 of Entrants } \\
\hline Threshold & $\begin{array}{c}0.045^{* *} \\
(0.019)\end{array}$ & $\begin{array}{c}0.041^{* *} \\
(0.019)\end{array}$ & $\begin{array}{c}0.041^{* *} \\
(0.019)\end{array}$ & $\begin{array}{c}0.040^{* *} \\
(0.018)\end{array}$ \\
\hline Constant & $\begin{array}{c}-0.120^{* * * *} \\
(0.022)\end{array}$ & - & - & - \\
\hline Year FE & $\mathrm{N}$ & $\mathrm{Y}$ & $\mathrm{Y}$ & $\mathrm{Y}$ \\
\hline Sector FE & $\mathrm{N}$ & $\mathrm{N}$ & Y & Y \\
\hline Province FE & $\mathrm{N}$ & $\mathrm{N}$ & $\mathrm{N}$ & Y \\
\hline No. of Observations & 37862 & 37862 & 37862 & 37862 \\
\hline Dep. Var.: $\Delta$ Log Exitor: & & & & \\
\hline Threshold & $\begin{array}{c}0.019^{* *} \\
(0.009)\end{array}$ & $\begin{array}{l}0.016^{*} \\
(0.009)\end{array}$ & $\begin{array}{l}0.016^{*} \\
(0.009)\end{array}$ & $\begin{array}{c}0.018^{* *} \\
(0.008)\end{array}$ \\
\hline Constant & $\begin{array}{c}-0.120^{* * *} \\
(0.022)\end{array}$ & - & - & - \\
\hline Year FE & $\mathrm{N}$ & Y & $\mathrm{Y}$ & $\mathrm{Y}$ \\
\hline Sector FE & $\mathrm{N}$ & $\mathrm{N}$ & $\mathrm{Y}$ & Y \\
\hline Province FE & $\mathrm{N}$ & $\mathrm{N}$ & $\mathrm{N}$ & $\mathrm{Y}$ \\
\hline No. of Observations & 37862 & 37862 & 37862 & 37862 \\
\hline
\end{tabular}

